\title{
THEY AND ITS LEMMAS AS NON-BINARY THIRD PERSON SINGULAR PRONOUNS IN THE WASHINGTON POST
}

\author{
Tantri R. Indhiarti, Dwi I. Rizki \\ Universitas Brawijaya \\ tantri.refa@gmail.com
}

Received: 30-02-2018

Revised: $05-03-2018$

Accepted: 19-03-2018

\begin{abstract}
This paper aims at elaborating how pronouns they, them, their, theirs, and themselves are used as singular ones in the articles of The Washington Post published in 2016. With the aid of corpus instrument software, this study qualitatively analyses a small corpus consisting of 100 articles. References of pronouns identified as singular are proceeded as the data source of this study and categorized into (Crystal, 2003) main classes of noun and (Cobuild, 2011) classification of indefinite pronoun. The study reveals that The Washington Post used they as singular with the references of proper noun which consists of names of people and organizations, common count concrete noun which consists of nouns denoting persons and a noun denoting things, common count abstract noun consisting of nouns denoting abstract entities, and 6 indefinite pronouns which are used to refer to persons. These references are found mostly to be non-referential, where gender is indefinite. However, some are found to be referential which are common count concrete noun child and proper nouns in the form of names of people. These references refer to individuals who identify themselves not in one of gender binaries, instead they are found to be used in a context regarding LGBT.
\end{abstract}

Keywords: singular they, non-binary pronoun, corpus, the Washington Post

\section{INTRODUCTION}

Most of languages in the world have pronoun as a part of speech. The use of pronoun in a discourse is inevitable as pronoun is used in order to not making repetitive mentioning of the said reference. Pronoun is also used to distinguish animate beings from inanimate entities, personal from non-personal beings, and male from female sexes by correlating with nouns in precise ways. However, according to (Crystal, 2003), in parsing noun modern grammars disregard the criterion of noting gender. It is because gender is less important category in modern English (Biber, D., Johansson, Leech, Conrad, \& E. Finegan., 1999). The wording can be found in the properties of masculine he, feminine she, and neuter it. He and she which refer to males and females respectively and it referring to entities neither male nor female are identified as the main use of the pronouns he, she, and it. The pronouns show that English pronoun is not as strongly grammaticalised as in other languages (Huddleston \& Pullum, 2002).

Be that as it may, pronoun still has ways to identify gender. As how the use of English pronoun separates the identification of natural gender male and female, it is clear that English lacks non-binary third-person singular pronoun. This lack rise problem when third-person pronoun must be used to refer back to indefinite reference such as everyone. Ideally, pronoun with indefinite reference must use either he or she. According to Baron (n.d.) in Standard English grammars, pronouns are supposed to agree with their references in number and gender. If he is used, it is considered sexist as he can mean both generic and male person. If she is used, it seems too self-consciously political because the generic feminine found to be used in $20^{\text {th }}$ century by feminist writing as an antidote to the generic he. When both are used, it makes the writing cumbersome. This is when the use of they as non- binary third-person singular pronoun emerges. It has been there used by many speakers and writers hundred years ago (Baron, n.d.).

Many words have been coined to fill the lack of English non-binary third- person singular pronoun. According to (Crystal, 2003) none of the proposals for a non-binary third-person singular pronoun has attracted much support. In informal speech, the use of singular they is widespread for indefinite reference, but it attracts criticism from those who feel that a plural word should not be made to refer back to a singular one. In this case, (Crystal, 2003) classifies noun into six main classes: proper noun, common noun, count noun, non-count noun, abstract noun, concrete noun, and pronoun. These types of noun can be replaced by pronouns as they carry out a similar range of functions to nouns and noun phrases. (Cobuild, 2011) divided pronouns into several types: personal pronoun consisting of subject and object pronouns, possessive pronoun, and reflexive pronoun, they referring to people in general and indefinite pronoun.

Unlike (Crystal, 2003), Baron (n.d.) believes that they as a word which originally exists in English and has been used as singular pronoun since hundred years ago, has the lead to fill the role. Baron (n.d.) calls the coined pronouns as the words that failed and regards singular they as one which has succeeded. This is apparent from they throned as Word of the Year in 2015 by American Dialect Society. Quoted from the website of American Dialect Society, they was recognized by the society for its emerging use as a pronoun to refer to a known person, often as a conscious choice by a person rejecting the traditional gender binary of he and she (Marquis, 2016). The Washington Post copy editor, Walsh, describes they as the only sensible solution to English's lack of a gender-neutral third-person singular personal pronoun (Walsh, 2015).

Walsh, alongside his statement regarding 
pronoun they, declared in an article published on December 8, 2015 that The Washington Post would adapt they as non-binary third-person singular pronoun in Post's stylebook. From this fact that they is adopted to be used differently for what it has to be grammatically, the researchers conduct the study to find out its use in The Washington Post. The trigger of this acknowledgement seems coming from the rising number of people as news source who give the authenticity of the news provided for Post requesting their gender not to be classified to gender binary, which is either male or female. As how (Walsh, 2015) states:

What finally pushed me from acceptance to action on gender-neutral pronouns was the increasing visibility of gender-neutral people. The Post has run neither at least one profile of a person who identifies as neither male nor female and specifically requests they and the like instead of he or she. Trans and gender queer awareness will raise difficult questions down the road, with some people requesting newly invented or even individually made-up pronouns.

Many studies related to pronoun they have been conducted since at least 1970s (Merkhofer, 2013) One of the many studies is an article titled In Search of Gender Neutrality: Is Singular They a Cognitively Efficient Substitute for Generic He? by (Foertsch \& Gernsbacher, 1997) which proved that they worked fine as singular pronoun to refer to nonreferential antecedents as substitute for genderspecific third-person pronoun he and she. (Foertsch $\&$ Gernsbacher, 1997) used quantitative approach to calculate the result of experimental stimuli. The data of the study were the reading time of native English participants.

Another study conducted on real life use of singular they is a thesis written by (Merkhofer, 2013) entitled She, He and They Trending on Twiter: Polyvocal Pronouns and More-Public Messages. In this study, Merkhofer examined the use of standard third-person personal pronouns he and she and singular they for a specific reference in a Twitter corpus. The referent had been decided through Twitter corpus used which it differs from the present study. The researcher conducted the present study to find out the various reference the pronouns referred to, the opposite of Merkhofer's study which was focused on pronouns' standard use. Quantitative was used as the study approach. The result of the study was that singular they was linked to the specific reference of the corpus and occurs at the same frequency as she and he while the hypothesis was that singular they was unlikely linked with the reference. The basic difference between the present study and the previous studies is that the present study was conducted to see whether singular they was used as non-binary third-person pronoun to refer to reference which is supposed to be gender-specific while the two previous studies focus solely on the use of they to refer to reference whose gender is indeterminate.

The importance of this study therefore is that the language phenomenon discussed may lead to wider acknowledgment on pronoun they as nonbinary singular aside from the plural use for the Washington Post is one of the leading international newspapers. It would also answer the lack of English non-binary third-person singular pronoun whose the issue itself has been brought over hundred years ago and still does not have a clear answer for the solution. Furthermore, the language phenomenon of real life use of pronoun they and its lemmas may answer the question how exactly they have been used as singular in journalism as Zimmer, a language columnist for the Wall Street Journal, states that style guide sometimes move in baby steps (Andrews, 2017). The change in the stylebook of The Washington Post by including singular they implies that the pronoun is endorsed to be used singularly even though it prefers to be avoided if any other way is possible (Walsh, 2015).

In line with the rationale described in the background, this study is to answer the following question: how are pronouns they, them, their, theirs, and themselves used as non-binary singular pronouns in articles of the Washington Post published in 2016? It is done by finding out the references of the pronouns, determining their classification of noun subclasses and a certain type of pronoun, and looking the use of the pronouns further into their larger context.

\section{METHOD}

A small corpus was built consisting of 100 articles sampled from The Washington Post website. As the data source consisted of numerous clauses and sentences, the use of a corpus instrument was imperative to enhance data analysis. In order to be able to see the singular use, qualitative approach that is an analysis that does not rely on numeric data (McEnery \& A, 2012) was used. It was because the pronouns found could not be described as plural or singular merely from the key word in context (KWIC) window of the corpus instrument; instead, a larger context was needed.

The data were obtained from online articles of The Washington Post published in 2016 and thus the data were sentences in those articles containing pronouns they, them, their, theirs, and themselves. As the use of the five pronouns as singular was the focus of the research, snowball sampling method was employed to obtain the articles containing the use of singular they. It is a non-probability or nonrandom sampling method used when characteristics to be possessed by samples are rare and difficult to find (Dudovskiy, 2011).

Before the articles were analysed, it was necessary to convert them into txt format as the format is suited and manageable in corpus software namely AntConc software. The software is a freeware corpus analysis toolkit for concordance and text analysis (Anthony, 2014). It has been facilitated with various function tools, such as concordance tool, concordance plot tool, file view tool, clusters/ngrams, collocates, word list, and keyword list. The software performs concordance which is a list of 
target words extracted from a given text or set of texts presented to indicate the context in which the word is used. This was done by clicking File then
Open File to choose the txt files. The next step is to entry the five pronouns in the search term bar by clicking start.

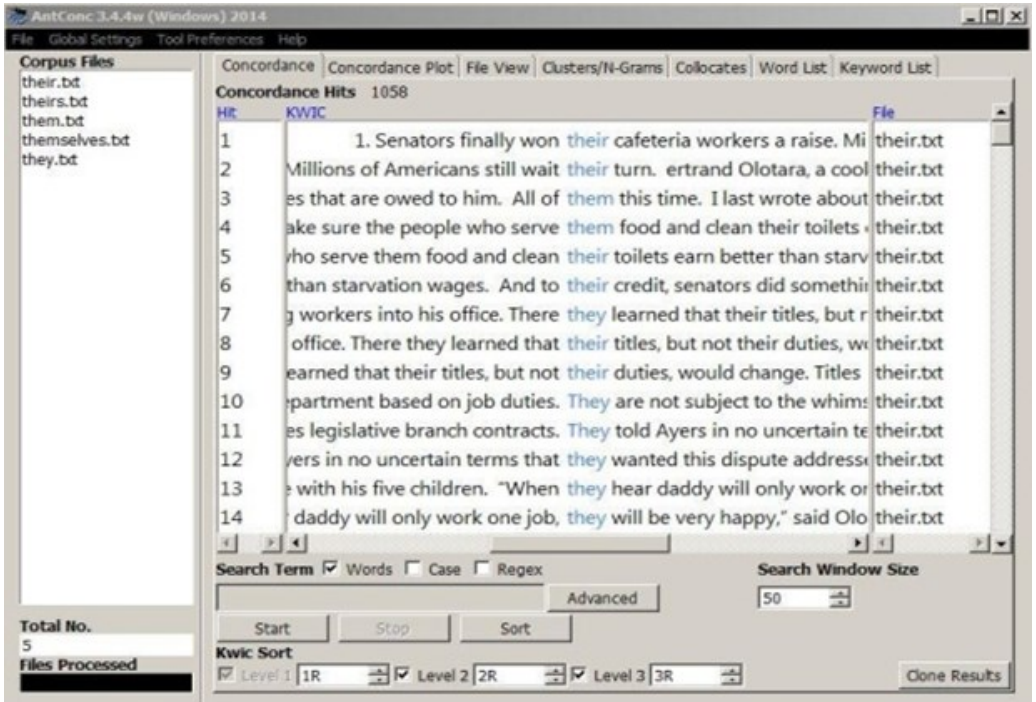

Figure 1 Concordance Tool of AntConc Software

In analysing the data, the references of pronoun they and its lemmas were figured out. A categorization of references was then made whether they were indefinite pronoun, proper noun, common count concrete noun, common count abstract noun, common non-count concrete noun, and common non -count abstract noun. The categorization was based on (Crystal, 2003) classification of noun and (Cobuild, 2011) classification of indefinite pronouns.

\section{III.CONCEPTS AND THEORETICAL FRAMEWORK}

\section{A. Noun}

Noun denotes all kinds of physical objects, such as persons, animals and inanimate objects. Identifying English nouns with the description of words denoting all kinds of physical objects (people, animals, places, things) and substance such as apple, $\mathrm{dog}$, and fire is unlikely because there are also large number of nouns denoting abstract entities such as absence, debt, and fear. (Crystal, 2003) defines noun according to four factors which involve in the way nouns behave; (1) syntactic structure: a noun is the chief item or head of a noun phrase and often preceded by one of a small class of determiners;(2) syntactic function: a noun functions as the subject, object, or complement, of a clause; (3) grammatical morphology: a noun can change its form to express a contrast in singular/plural number or to mark the genitive case; (4) lexical morphology: a noun can be formed by adding one of a small list of suffixes to a verb, an adjectives, or another noun.

(Crystal, 2003) classifies noun into six main classes, namely proper noun, common noun, count noun, non-count noun, abstract noun, and concrete noun as follow:

1) Proper Noun and Common Noun

Proper nouns are names of specific people, places, times, occasions, events, publications, and so on. They differ from common nouns in three main ways: (1) proper nouns can stand alone as a clause element (I like London, Fred is here), whereas only certain common nouns can (Egg is bad, I see cat); (2) Proper nouns do not usually allow a plural (Londons, Freds). Whereas most common nouns do (books, eggs); (3) Proper nouns are not usually used with determiners (a London, the Fred), whereas common nouns are (a book, the music). However in some circumstances, proper nouns can behave like common nouns (I hate Mondays, I used to know a Mary Jones).

2) Count and Non-count Noun

Common nouns can be divided into two types. Count nouns refer to individual, countable entities (books, eggs) and non-count nouns or mass nouns refer to an undifferentiated mass or notion (butter, advice). There are three clear grammatical differences between them: (1) count nouns cannot stand alone in the singular while non-count nouns can; (2) count nouns allow a plural while non-count nouns do not; (3) count nouns occur in the singular with a while non-count nouns with some and both types can occur with the.

\section{3) Abstract and Concrete Noun}

Both count and non-count nouns can be divided further into abstract and concrete. Concrete nouns refer to entities which can be observes and measured (book, car) while Abstract nouns refer to unobservable notions (difficulty, idea).

\section{B. Pronoun}

Pronouns can replace a noun, a noun phrase, and refer to a very general concept which includes the meaning of many possible noun phrases, and to some unspecified event of the situation. According to (Crystal, 2003) pronouns are words which stand for a noun, a whole noun phrase, or several noun 
phrase. They carry out a similar range of functions to nouns and noun phrases. They can appear as subject, object, or complement of the clause. However, they differ from nouns chiefly in not usually permitting modification (a big car, but not a big it).

(Cobuild, 2011) divides pronoun into several types. The researcher only focuses on types of pronoun which correlate to the use in data source which are all variation of pronoun they and indefinite pronoun.

1) Personal Pronoun

\begin{tabular}{|c|c|c|}
\multicolumn{3}{|c|}{ Table 1 Subject Pronouns } \\
\hline Person & Singular & Plural \\
\hline $1^{\text {s }}$ person & I & we \\
\hline $2^{\text {nd }}$ person & \multicolumn{2}{|c|}{ you } \\
\hline $3^{\text {rd }}$ person & $\begin{array}{c}\text { he } \\
\text { she } \\
\text { it }\end{array}$ & they \\
\hline
\end{tabular}

2) Possessive Pronoun

Table 2 Possessive Pronoun
\begin{tabular}{|c|c|c|}
\hline Person & Singular & Plural \\
\hline $1^{\text {st }}$ person & mine & ours \\
\hline $2^{\text {nd }}$ person & \multicolumn{2}{|c|}{ yours } \\
\hline $3^{\text {rd }}$ person & $\begin{array}{c}\text { his } \\
\text { hers }\end{array}$ & theirs \\
\hline
\end{tabular}

3) Reflexive Pronoun

\begin{tabular}{|c|c|c|}
\multicolumn{3}{|c}{ Table 3 Reflexive Pronoun } \\
\hline Person & Singular & Plural \\
\hline $1^{\text {st }}$ person & myself & ourselves \\
\hline $2^{\text {sd }}$ person & yourself & yourselves \\
\hline $3^{\text {rd }}$ person & $\begin{array}{c}\text { himself } \\
\text { herself } \\
\text { itself }\end{array}$ & themselves \\
& & \\
\hline
\end{tabular}

\section{They Referring to People in General}

According to (Cobuild, 2011), pronoun they and its lemmas can also be used to refer people in general. They can be used to refer to an individual you do not know, or do not want to specify, whether the individual is male or female. This use is very common to refer to:

1) the indefinite pronouns anyone, anybody, someone, somebody, everyone, everybody, no one, and nobody.

Example:

If I think someone is having problems, I will spend hours talking to them.

2) b. singular nouns such as person, parent, and teacher, which do not specify whether the person is male or female.

Example:

A person's body fat determines how

long they can withstand cold water.
3) noun phrase with the determiner each, every and any.

Example:

We want every player to push themselves to get into the team.

\section{IV.RESULT AND DISCUSSION}

From the articles in The Washington Post, 5 keywords searched were found to be having 1058 concordance hits. Yet using (Crystal, 2003) classification of noun and (Cobuild, 2011) classification of indefinite pronouns, only 111 hits were found as singular use. The samples of these references are put in the following table:

\begin{tabular}{|c|c|c|}
\hline No. & Pronoun & Reference \\
\hline 1 & \multirow{5}{*}{ They } & Jacob Tobia \\
\hline 2 & & a person \\
\hline 3 & & Zzyym \\
\hline 4 & & Pidgeon Pagonis \\
\hline 5 & & anyone \\
\hline 6 & \multirow[t]{4}{*}{ Them } & your child \\
\hline 7 & & the latest service disruption \\
\hline 8 & & everyone \\
\hline 9 & & a saint \\
\hline 10 & \multirow[t]{3}{*}{ Their } & a transgender person \\
\hline 11 & & the final group \\
\hline 12 & & that candidate \\
\hline 13 & Theirs & - \\
\hline 14 & \multirow[t]{3}{*}{ Themselves } & Jacob Tobia \\
\hline 15 & & no one \\
\hline 16 & & the new rule \\
\hline
\end{tabular}

\section{A. Indefinite Pronoun}

Indefinite pronoun is a pronoun referring to unspecified thing or person. (Cobuild, 2011) classifies indefinite pronoun into 12 , with 8 were used to refer to a person or people. It was found that 6 out of the 8 pronouns were used, which were anyone, everybody, everyone, no one, somebody, and someone. Although everybody and everyone are semantically plural, they both require singular verb, making them to be grammatically correct in standard English according to Baron (n.d.) to fulfil the agreement in number if they use one of third-person singular pronouns she or he to refer back to them. However, The Post used they to refer to them instead of choosing between she, he, or even using both as he/she in their writing, albeit they does not quite fulfil the agreement in both number and gender. It can be seen from the following excerpts:

[Their-1] Virtually everyone sees drowsy driving as a serious threat to their safety, but more than 30 percent said they have had trouble keeping their eyes open while driving in the past 30 days.

[Their-29] Everybody is held to that level of excellence. Everybody from the coaches to the players to the janitors - everybody in that building is doing their best job.

While no one semantically means "no person", 
RETORIKA: Jurnal Ilmu Bahasa, Vol. 4, No. 1 April 2018, Page 21

it requires singular verb, like the rest of indefinite pronouns. To thrive on the correct grammar in Standard English, according to Baron (n.d.), the pronoun is supposed to agree with the reference in both number and gender. Seen from the singular verb, she or he should fulfil the agreement in number but not in gender. Neither of them was used by The Post to refer to no one and they was used instead, although it does not quite fulfil the agreement in both number and gender as seen from the following excerpts:

[Themselves-3] Instead of changing bodies, I wish we could change our society to one that accepted feminine boys and men and masculine girls and women so that no one felt compelled to expose themselves to the risks of life-long hormone administration or the removal of healthy organs.

Anyone, somebody, and someone are able to semantically mean singular or plural as they can be used to refer to one, some, every or all person(s) without specification. Despite their semantic meaning, they require singular verbs. As they refer to person(s), she or he should have been used for grammatical correctness of Standard English according to Baron (n.d.) to fulfil the agreement in number if seen from the singular verb. The Post did not use either as seen from the following excerpt:

[They-55] But anyone who wants to be president should be happy to show that they support our government appropriately.

[Them-14] Nobody actually cares about political lying, and if somebody

tells you otherwise, don't believe them.

[Them-6] The best way to understand someone is to know them.

\section{B. Common Noun}

Indefinite references aside from indefinite pronoun were also found. These references were singular nouns used in a context referring to said persons in general thus specifying gender was not necessary. These singular nouns were categorized into four common noun categories. However, only two categories were found which were common count concrete noun (CCC) and common count abstract noun(CCA).

Common noun is a noun referring to a class of entities, be it a person, place or thing. Common noun reference was categorized from the head of the noun phrase. CCC references found were mostly modified by definite and indefinite determiners with the heads: driver, person, candidate, man, saint, parent, child, group, and weapon. The first six nouns mentioned referred to an unspecified person, child referred to a specified person, while group referred to a unity consisting of several persons, and weapon referred to a class of thing. The modification of these heads can be seen from Table4.1.
Below is one example of common noun modified by indefinite determiner:

[They-29-30] A man is a man no matter what they call themselves.

The excerpt above shows that pronouns they and themselves referred to singular noun a man, which head is man and modified by an indefinite determiner $a$. Noun man aside from having meaning as a male person, it also has plural meaning which refers to all living human. However, the man did not refer to the latter as an indefinite determiner $a$ was used as an indication that singular meaning took place in the context. Instead of using generic he as how it was quite convenient since the noun man has a meaning of a person with male gender and the context where the speaker of this utterance referred to male persons, pronouns they and themselves were used instead. Below is one example of common noun modified by definite determiner:

[They-19-20] Many cisgender heterosexual folks are going to consider and take a moment to ponder: This person is attractive, and they're in my dating pool.

They was found referring to noun phrase this person whose head is person modified by a definite determiner this. The use of definite determiner entailed that the noun was specified, which means it was supposed to be able to be identified. However, this person here was used in a hypothetical context or if-situation. Therefore, even though the noun person was modified by definite determiner this, it actually referred to no one in particular, or not a specific person.

It was found that noun child modified by definite determiners our, your, and the, as the references of singular they, referred to a specified person. An example with one modified by definite determiner our can be seen from the following excerpt below:

[Them-8] Our child has asked for us to call them her/she/sister and Ellie is a name she chose once she realized people would think she was a boy with her birthname.

It can be seen that pronoun them was used to refer to singular reference our child. As child is a singular noun denoting a young person, third-person pronoun her or him should have been used to be grammatically correct as her or him fulfilling agreement in both number and gender but them was used instead. The reference was a noun phrase our child with the head child modified by a definite determiner our. Although the other nouns modified by definite determiner referred to unspecified person, noun child was found to be a different case.

After examining the whole article where this sentence was originated, it was found that our child here referred to a transgender child named Ellie. As it can be seen, Ellie was referred using both genderspecific third-person pronoun she and singular they. The use of singular they referring to Ellie in the 
article indicated and somewhat emphasized that Ellie was a transgender child. Since Ellie was still a child, it was assumed that pronoun preference for Ellie could change as Ellie grows up. Later in the article where it told how Ellie wanted to be referred as a girl, gender- specific she took the place of singular they.

[They-49] One group was told they would begin receiving health insurance premium discounts on a biweekly basis immediately after reaching their weight-loss goal,

One group was the reference of pronouns they and their. This reference was a noun phrase with the head group modified by an adjective one indicating one entity of a group. The noun group was not only able to be classified as a common noun, but also able to be specifically classified into collective noun, a singular noun indicating that it is a collective of people or things. Collective noun is able to be treated as plural or singular according to context. In the excerpt, collective noun group was used as singular since it was used with singular verb was. A collective noun is followed by a singular verb when the impersonal unity of collective of people or things is focused or addressed. Since the group here was followed by singular verb, it and its should have been used as they are the grammatically correct ones as (Cobuild, 2011) states that referring to a collective noun, a singular pronoun or determiner is used if the previous verb is singular. However, looking from the context, The Post used they and their instead to address the collective of people in the group impersonally since if it and its are used, the people will be failed to be addressed, but the existence of one group will.

[Them-11] And he explicitly said he would not object to Japan acquiring a nuclear weapon because "it's not like, gee whiz, nobody has them."

It can be seen from the excerpt above that them referred back to a noun phrase a nuclear weapon with the head weapon modified by an indefinite determiner $a$ and an adjective nuclear. To be grammatically correct, pronoun it should have been used. Although them was in quotation of someone's utterance, The Post chose to maintain this form while certainly, the sentence presented could be paraphrased in such a way where quotation of utterance was not used so them could be replaced by it as it should have been used to refer back to the singular reference denoting a thing which is $a$ nuclear weapon. CCA references were only found twice, with the heads disruption and rule as their modification.

[Themselves-4] This is a benefit of inversion, and by curbing it, the new rule may deter inversions themselves.

The noun rule is an abstract entity, which it cannot be touched physically but can be counted, thus categorized into count abstract. As it is a countable noun, singular verb is required making itself grammatically correct to be used instead of themselves to fulfil the agreement in number according to Baron (n.d.).

\section{Proper Noun}

Proper noun is a noun made of name of a person, place or organization written in initial capital letter. Eleven proper nouns were found to be the references of singular they. Five of them were the names of organization or group which were ADAMS Center, the NFL, the Republican party, the New York Times, and the GOP. These references were found to be treated like collective noun in the context. Singular verb was used for them to represent them as one impersonal unity. Although they were referred impersonally, pronouns they were used instead of it which should have been the grammatically correct one in fulfilling agreement in number. Looking from the context, the use of they instead of it by The Post was to point out and emphasize that these references consisted of people, not mere unity with a name of said organization without people controlling behind it.

[Their-31] The GOP apparently feels that a contested convention with a full chairswinging wrestlethonatron and a candidate such as Cruz (or somebody who nobody voted for) is going to clean up and heal the massive split in their party.

The GOP as the subject here, which is an abbreviation for Grand Old Party referring to Republican Party which is one of two major political parties of United States, used singular verb as seen from the $-S$ in the verb feel. As the use of singular verb meant that The GOP was referred as an impersonal unity rather than the members inside the party, third-person pronoun for non-person its should have been used to be grammatically correct as the pronoun fulfils the agreement in number.

The other six proper nouns found were the names of people which were Jacob Tobia, Pidgeon Pagonis, Zzyym, Munir, Park, and Brennan Lewis. English only provides two choices of third-person singular pronoun to refer to a person, and both are not gender-neutral or non-binary. Instead of using the gender-specific she or he to refer to these six people to be grammatically correct, The Post chose third-person pronoun they which was supposed to be used as a plural as seen for the following excerpt:

[They-21] For Munir, it was the first time they had stood up and publicly disclosed their gender identity to anyone.

The finding of this study demonstrates that they had been used as singular with the reference of indefinite pronoun and indeterminate gender as Miller and Swift (Merkhofer, 2013) state and as Baron (Merkhofer, 2013) finds that singular they has least resistance when used in places where it is syntactically singular but semantically plural. Such references had been found and categorized in this 
study into indefinite pronoun, common noun, and also proper noun.

In this study, it was found that singular they was mostly used by The Post to refer to non referential antecedents or references whose gender was presumably unknown or was not quite the matter in the context. Such references found in this study were for example everybody (indefinite pronoun), a person (common noun), and the GOP (proper noun). Singular they with such references were predicted to be used as (Foertsch \& Gernsbacher, 1997) have proven that singular they is cognitively efficient substitute for generic he or she. Furthermore, singular they referring to indefinite pronoun references have been endorsed by many grammar books, in which this study used is one by (Cobuild, 2011) The fact implies that the use is quite common, as it was predicted as one between the findings of this study.

Common noun modified by definite determiner usually entails that the noun phrase formed is able to be specified or identified. Despite common noun person was found to be modified by definite determiner the and this, they did not form noun phrases denoting referential antecedents or references whose gender was assumed to be known. This conclusion was drawn after further examination of the articles where the references were found. All of them were used in a hypothetical concept where not a specific or particular person was addressed. Common noun child however, was found to be modified by definite determiner your, our, and the with all forming noun phrases as references whose actually refer to a specific person. All these references formed with child as the head and said definite determiners were found in one article whose context was about LGBT as seen from the following excerpt:

[Their-25] The best way to protect your child is to let them know they need to follow what their parents say instead of the child doing what they want.

Another note about common nouns found, even though (Foertsch \& Gernsbacher, 1997) empirical research resulted in they as a suitable substitute for gender-stereotyped noun compared to pronoun of the opposite gender stereotype, all found common nouns referring to person in this study were genderneutral or not gender-stereotyped: driver, person, man, child, parent, candidate, and saint.

Nouns which were the names of organizations or groups were also found: ADAMS Center, the NFL, the Republican party, the New York Times, and the GOP. These nouns categorized into proper noun were treated like collective noun where singular and plural meaning can take place according to context. It was concluded as such for a similar reference (the Colts) was found to be used as a plural by The Post in different context as seen from the following excerpt:

The Colts were smart with early-round choices, too: From 2001 to '03, their top selection was receiver Reggie Wayne, pass-rusher Dwight
Freeney and tight end Dallas Clark - a trio that eventually combined for 14 Pro Bowls.

This entailed that The Post did not only use such references only as singular. Furthermore, by comparing from the context where the Colts and the proper nouns above were found, it was apparent whether the writers meant to refer to them as a singular, an impersonal unity, or as plural, when people inside the unity are addressed. The noun the Colts, as in American football team Indianapolis Colts, was used in a sentence after sentences which talked about some of the team's members thus making the noun referred as plural as attention was being drawn to the individual members of the Colts. These nouns were referred as corporate nouns, nouns referring to groups of people who form a functional unit, by (Foertsch \& Gernsbacher, 1997).

Further findings which were not the part of the majority non referential, were proper nouns denoting the names of people: Jacob Tobia, Pidgeon Pagonis, Zzyym, Munir, Park, and Brennan Lewis. The names implied that they were clearly referential, where gender must be known and not only assumed or stereotyped. It was found that all of these names were found in articles whose contexts were about LGBT. After further examination of the articles, it was concluded that all of these people did not identify themselves as either male or female: (1) Jacob Tobia was a trans writer who was explicitly stated by The Post in the article that Tobia used singular they to refer to themselves; (2) Pidgeon Pagonis' preferable pronoun was not stated by The Post but it was stated that Pagonis was born intersex and identified as both queer and gender queer. Later, in the following sentences of this statement, The Post used they to refer to Pagonis as seen from the following excerpt:

[They-6] Pidgeon Pagonis was born intersex and identifies as both queer and gender queer. They later underwent surgeries as a child to remove traces of male sex traits and was put on hormones to force them to go through puberty as a girl.

(3) Zzyym was a person who identified themselves as intersexual, as Zzyym was born as a hermaphrodite. It was also clearly stated by The Post in the article that Zzyym preferred to be addressed with singular they; (4) Munir was a non-binary person and The Post used a notice after several uses of singular they referring to Munir in the said paragraph that Munir used gender-neutral pronouns; (5) Park identified themselves as queer and gender queer. The Post also mentioned that Park referred to themselves using singular they instead of thirdperson singular he; (6) Brennan Lewis identified as gender queer and it was also clearly stated by The Post that Lewis used gender-neutral pronoun to refer to themselves.

In short, the pronouns were used not without notice or explanation beforehand. When the pronoun was being mentioned for the first time in the respective article to refer to these people, a notice or 
RETORIKA: Jurnal Ilmu Bahasa, Vol. 4, No. 1 April 2018, Page 24

explanation was written to prevent readers' confusion before proceeding further into the story of the respective article. Although notice or explanation had been given, confusion of what the pronoun actually referred to still occurs which can be seen from the following excerpt:

[Their-7] Adding to the physical pain was the emotional - their parents never told Zzyym about the birth certificate or surgeries, leaving them to wonder what, exactly, they were.

In the sentence, two entities, one plural and one singular were mentioned, their parents and Zzyym. The pronouns them and they mentioned afterwards could refer to both their parents and Zzyym, their parents, or Zzyym alone. If context and notice are ignored altogether, comprehension of what them and they refer to is quite inconceivable. Another note, it can be noticed that the use of pronoun to replace the noun Zzyym was placed carefully. As the article where the proper noun Zzyym was found, it was about the story of Zzyym alone, where hardly person other than Zzyym was mentioned. However, instead of referring to Zzyym with they, the noun Zzyym was reused numerous times where pronoun should be able to take place. Thus, it can be concluded that when The Post used singular they to refer to a referential antecedents of proper noun, a reference whose gender is actually known, The Post combined the repetitive use of last name and singular they to make either's use less awkward (by keep repeating last name) and less confusing (as they also refers to plural noun, like the case above).

After having the findings and analyses of this study discussed, it is worth to compare it with the previous studies. The two of them were concerned with singular they however, they were conducted from different scope. The first study is that of (Foertsch \& Gernsbacher, 1997). They made an experiment to compare reading time of three-clause sentences consisting different pronouns of thirdperson pronouns she, he, and they by native English participants. The sentences consisted of antecedents that were indefinite pronouns and common nouns which were stereotypically masculine, feminine, and gender neutral.

The results of the experiment were that clauses containing they were read (a) much more quickly than clauses containing a gendered pronoun that went against gender stereotype of the antecedent, and (b) just as quickly as clauses containing a gendered pronoun that matched the stereotype of the antecedent. However, with referential antecedents, for which the gender was presumably known, clauses containing singular they were not read as quickly as clauses containing a gendered pronoun that matched the antecedent's stereotypic gender. In other words, the study demonstrated that singular they was a cognitively efficient substitute for generic she or he, particularly when the antecedent was nonreferential. This study did not include the possibility of the antecedent being a specific or clearly known person, not mere assumed of whom gender is known, unlike the current study, as the issue of pronoun they used to refer to nonconforming person itself has only raised currently in recent years. Be that as it may, the study helped the current study to picture what kinds of reference were going to appear referring to singular they.

The second previous study is one conducted by (Merkhofer, 2013). She conducted a study of Twitter corpus with an assigned reference which was a trending hash tag \#oomf, the abbreviation of one of my followers. This reference was specific, or referential in which gender was presumably known. Three pronouns were examined to see how Twitter users preferred referring to referential antecedent, a person whom gender was assumed to be known. It was found that the three of the pronouns occurred in the same frequency in the Twitter corpus even though they was considered to be unlikely.

(Merkhofer, 2013) also emphasized that two texts including singular they were disseminated by many users, while tweets containing standard pronouns accumulated only small-scale social action thus implied that they was available as a pronoun of self- identification and if the usage spreads more widely, it will affect the possibilities of they for all singular people in the future, in which one of those usage spreads is one endorsed by one leading US newspaper The Washington Post, the focus of the current study. The data collected of Merkhofer made it far outside the possibility to identify the gender identification implied behind who was actually referred as one of my followers by Twitter users. This differentiates the current study as researcher examined further into context to find out whether nonreferential or referential antecedents were referred by singular they. Furthermore, looking into context also made the researcher able to identify the gender if the antecedents were referential.

Both previous studies were conducted from different scope and the similarity between the two and the current study only stops at singular they being the main concern. It distinguishes the current study with the two as they only concerned with singular they with reference whose gender was assumed to be known, not with reference whose gender was not only assumed, but specific and could be clearly identified. Studies about pronoun they have been conducted since at least 1970s but it is only recently that the pronoun is used to refer to singular person who is comfortable to use the pronoun as self-identification, who does not refer to themselves as one of gender binary.

Furthermore, studies concerning singular they referring to them is worthy conducting and examining, as (Merkhofer, 2013) states that if the usage spreads more widely, it will certainly affect the possibilities of the pronoun used to refer to all singular people in the future. The current study had been conducted to examine one of the usage spreads, to see how singular they was used by The Washington Post, how the pronoun was endorsed by one leading US newspaper. It was a corpus-based study, where a corpus software helped the researcher to build a small corpus consisted of articles sampled and to enhance the analysis of the data. The corpus 
allowed the researcher to look and examine further where the pronoun was found to be used as singular in the context thus resulting in more descriptive and accurate findings.

Be that as it may, the researcher still found some limitations in conducting this study. The Washington Post only had added singular they to their stylebook in the end of 2015 which made the researcher only had the following one year, 2016, as the time span in collecting the data. Furthermore, The Washington Post stated that they would try to avoid the use of singular they except when the avoidance would result in awkwardness thus making it more difficult to find the use of pronoun they and its lemmas as singular.

\section{CONCLUSION}

Pronoun they and its four lemmas them, their, theirs, and themselves were used as singular pronouns in the articles of The Washington Post to refer to mostly indefinite references or nonreferential antecedents. However, referential antecedents or specified references were also found.

Further look into context, it was found that the specified references were only used in a certain context which was LGBT, while indefinite references were found to be in various contexts. This was concluded as such for common count nouns by looking at their syntactic structure, at how they were modified by determiners, while for proper nouns, they were singular nouns but were treated as plural with some of them were names of collective of people with the rest were names of persons. Individual persons were referred as plural as they were found to have one similarity, which was they belong to LGBT community, as persons who did not identify themselves in either gender of gender binary.

In short, The Washington Post had indeed applied their addition of singular they in the stylebook. However, the use referring to specified people is only reserved for LGBT context which suggests that the use is only endorsed so far in the community. The statement of (Merkhofer, 2013) of singular they usage spreads and the possibility of the pronoun to be used to all singular people in the future is still far in so many steps ahead. In this case, the search on pronoun they has begun long ago at least $1970 \mathrm{~s}$, but it is only recently that the pronoun is used to refer to singular people. It is thus worth to conduct a study of singular they to find out how other discourses use the pronoun. One of them is the Associated Press which has recently added singular they in their stylebook in late March 2017.

\section{ACKNOWLEDGMENT}

We would like to take a moment to say thank you in advance to the editor and reviewers who will participate in the peer review process.

\section{REFERENCE}

Andrews, T. . (2017). The singular, gender-neutral "they" added to the Associated Press Stylebook.

Anthony, L. (2014). AntConc (Version 3.4.3) [Computer Software]. In Japan. Waseda University.

Biber, D., S., Johansson, Leech, G., Conrad, S., \& E. Finegan. (1999). The Longman grammar of spoken and written English. In London. Longman.

Cobuild, C. (2011). English grammar. In Great Britain. HarperCollins Publishers.

Crystal, D. (2003). The Cambridge encyclopedia of the English language. United Kingdom. Cambridge University Press.

Dudovskiy, J. (2011). Snowball sampling.

Foertsch, J., \& Gernsbacher, M. A. (1997). In search of gender neutrality: Is singular they a cognitively efficient substitute for generic he? Journal of Psychological Science, 8(2), 106111.

Huddleston, R., \& Pullum, G. . (2002). The Cambridge grammar of the English language. In Cambridge. Cambridge University Press.

Marquis, M. (2016). 2015 Word of the year is singular "they."

McEnery, T., \& A, H. (2012). Corpus linguistics: method, theory and practice. In Cambridge. Cambridge University Press.

Merkhofer, E. M. (2013). She, he and they trending on twitter: Polyvocal pronouns and morepublic messages. Georgetown University.

Walsh, B. (2015). The post drops the "mike" - and the hyphen in "e-mail." 